\title{
Perceptions, behaviours, barriers, and needs of flipped classroom learning: opinions of first-year pharmacy students
}

\author{
Pei Se Wong (iD, Ket Li Ho iD, Chee Fen Chia iD, Sook Han Ng iD, Hazwanie Hashim iD \\ International Medical University, Malaysia
}

\author{
Keywords \\ Blended learning \\ Flipped learning \\ Learning strategies \\ Self-regulated learning \\ Correspondence \\ Pei Se Wong \\ Department of Pharmacy Practice \\ School of Pharmacy \\ International Medical University \\ Malaysia \\ peise_wong@imu.edu.my
}

\begin{abstract}
Objective: To explore pharmacy students' experiences, barriers, and needs of first-year pharmacy students flipped classroom (FC) learning. Method: A qualitative study with focus groups was performed. Three focus group sessions with seventeen first-year pharmacy students were conducted. All sessions were audio-recorded, transcribed, and analysed for themes using an inductive thematic analysis approach. Results: Students, in general, found FC to be useful for learning and using a range of self-regulated learning strategies in the FC environment. Barriers identified were primarily to i-lectures and potentially hindered motivation and acceptance to pre-classroom preparation. Conclusions: There are students' reservations toward flipped classrooms attributed to individual motivation and barriers encountered. Students transitioning to flipped classroom approach require easy-to-learn and use pre-class learning materials tailored to students' level and preferences.
\end{abstract}

\section{Introduction}

Traditionally, teaching has been conducted through supervised face-to-face classrooms but is now able to be conducted through the internet anywhere and anytime (Iwai et al., 2020). Blended learning is becoming increasingly popular, especially as we approach the new normal in the post-COVID-19 era. Among the different models of blended learning, in practice, the use of the flipped classroom (FC) teaching approach has become common in health professions education (Akcayir \& Akcayir, 2018).

Based on the studies in the contexts of health professions education, it has been observed that students favour the FC approach over the traditional classroom, and this approach improves the performance of the students (Chen \& Martinelli, 2017). In a typical traditional classroom, students listen to lectures in class and complete their homework after class. On the other hand, a typical FC consists of preclass activities followed by in-classroom human interaction FC (Lage, Platt, \& Treglia, 2000; O'Flaherty
\& Phillips, 2015). Pre-class activities could be interactive online tutorials, video lectures, or textbook readings.

Students' requirement to prepare using the pre-class activities before attending a class places strong demand for students' self-regulated learning skills (He et al., 2016). A study found those who lacked selfregulated learning skills would not fully benefit from the FC environment (Butzler, 2016).

Self-regulated learning (SRL) involves students actively controlling their learning process by using SRL strategies such as planning learning activities, selfmotivation, organising, repeating, self-monitoring, and evaluating their learning (Artino \& Stephens, 2009). While many theories and models of SRL have been proposed, all share similarities that learning occurs through distinct phases (Colthorpe et al., 2019). Zimmerman's model, one of the widely used models, theorised that SRL could be acquired through three phases with metacognitive strategies; goal setting and planning in the forethought phase, monitoring and self- 
control in the performance phase, and evaluation and adaption in the self-reflection phase (Zimmerman \& Moylan, 2009). Students can adjust their learning strategies to certain learning tasks and contexts. Medical students in an FC environment frequently used SRL learning strategies in the planning and reflection stages but less frequently during the learning or monitoring phase (Zheng, Ward, \& Stanulis, 2020). Pharmacy students can self-regulate their learning, but the learning strategies differ between students (Colthorpe et al., 2019). Not much is known of pharmacy students' learning strategies in FC or on such students' periods of transition to $\mathrm{FC}$ environment in the early stage of pharmacy education.

This study was conducted to explore students perceptions, behaviours, barriers, and needs of a large class size, which was designed by the principles of the FC approach. The specific research questions were 1) what learning strategies did the students adopt during an FC environment? and 2) what are the barriers and needs of students undergoing the FC teaching approach? The investigation of learning strategies was approached from the viewpoint of SRL metacognitive strategies (e.g. setting and planning, monitoring, and evaluation etc.) and the hindering factors of students' learning processes through the FC environment. Because quantitative studies cannot answer these issues, the present qualitative study sought first-year pharmacy students' views on transitioning to an FC learning approach. Findings could help educators customise blended learning into pharmacy education in the current era of the pandemic.

\section{Methods}

This study adopted a qualitative research methodology. A qualitative design was adopted due to the flexibility for an in-depth exploration of participants' experiences and intentions. Focus group interview (FG) was selected because it could promote questions, sharing, and exchange of opinions, ideas, and experiences (Kitzinger, 1995), and also allows generation of information on collective views (Gill et al., 2008). The strengths well fitted the purpose of the study to elicit collectively different students' experiences and views.

The study took place in a private medical and health sciences university in Malaysia that offers a Bachelor of Pharmacy (B.Pharm.) programme. The B.Pharm. programme uses $\mathrm{FC}$ as one of the teaching approaches. In Year one (Semester one), the FC approach was adopted in three modules: Biological Science (three credits) for topics on "protein as a catalyst" and "mendelian disorder", Pharmaceutical Organic Chemistry (four credits) for topics on "functional groups and nomenclature" and "amine" and General Chemistry (four credits) for a topic on "electrochemistry and colligative properties". These topics were delivered by five pharmacy faculty members. Each FC consisted of two phases where ilectures (online, pre-class lectures) preparation was followed by in-classroom activities. Students enrolled in year one of the B.Pharm. programme were invited to take part. The reason for choosing the year one student was because this group of students was exposed to the FC environment for the first time in the pharmacy programme. The study was approved by the University Research and Ethics Joint Committee (Project ID number: 338/2018).

All Year one students were invited to participate in the study via class announcement, followed by an email with a study information sheet. We purposively selected students of different genders who watched at least one i-lecture before the classroom because they would have information about the learning experiences of pre-class and in-classroom activities. Study participation was voluntary. Confirmation of the date and time of interviews was provided to consented participants.

All FG interviews were facilitated by a guide developed on the basis of a literature review and the study objectives. The interviews covered perception of overall FC learning experiences, pre-classroom and inclassroom activities and learning strategies, challenges, and suggestions to improve. The FGs were conducted by the principal (PSW) or second author (CFC). Before FG interviews, consented participants were reminded again of the purpose of study and data de-identification before interviews. Each FG comprised of five or six participants, lasted 55 minutes on average and was audio-recorded. Sampling, recruitment, and interviews continued until they did not elicit additional points to the overall concepts and themes.

Interviews were transcribed verbatim, and the transcripts were checked against the recordings for quality and accuracy. Thematic analysis using the inductive method (Clarke \& Braun, 2013) was used when analysing the data. Data organisation was facilitated using NVivo 10 software (QSR International Pty Ltd, 2020). Transcriptions were read and coded independently by PSW and CFC to increase the robustness of the analysis. Both PSW and CFC were not involved in FC teaching of the participants and had experience in qualitative analysis techniques, hence would have fewer assumptions or bias that could interfere with data collection and analysis. Regular meetings were conducted with all other authors to confirm the codes and identify possible groupings. This was followed by stages of reviewing and interpretation 
of each theme. The research team had regular discussions on the identified codes and themes.

\section{Results}

The characteristics of the participants are presented in Table I. Out of 67 students invited, 17 pharmacy students consented and participated in three focus groups. The age of the participants ranged from 19-20 years, and $59 \%$ were female.

Table I: Participant's demographics

\begin{tabular}{llllcc}
\hline $\begin{array}{l}\text { Partici } \\
\text { pants }\end{array}$ & Age & Gender & $\begin{array}{l}\text { Focus } \\
\text { Group } \\
\text { (FG) }\end{array}$ & $\begin{array}{c}\text { Number of } \\
\text { flipped } \\
\text { classroom } \\
\text { sessions } \\
\text { attended }\end{array}$ & $\begin{array}{c}\text { Number } \\
\text { of online } \\
\text { lectures } \\
\text { viewed }\end{array}$ \\
\hline P1 & 19 & Male & FG1 & 5 & 2 \\
\hline P2 & 19 & Female & FG1 & 5 & 3 \\
\hline P3 & 20 & Female & FG1 & 4 & 2 \\
\hline P4 & 19 & Male & FG1 & 5 & 5 \\
\hline P5 & 19 & Male & FG1 & 5 & 5 \\
\hline P6 & 19 & Female & FG1 & 4 & 5 \\
\hline P7 & 19 & Female & FG2 & 5 & 5 \\
\hline P8 & 19 & Female & FG2 & 5 & 1 \\
\hline P9 & 19 & Male & FG2 & 5 & 5 \\
\hline P10 & 19 & Female & FG2 & 5 & 5 \\
\hline P11 & 18 & Female & FG2 & 5 & 5 \\
\hline P12 & 19 & Male & FG3 & 5 & 5 \\
\hline P13 & 19 & Female & FG3 & 5 & 1 \\
\hline P14 & 19 & Female & FG3 & 5 & 3 \\
\hline P15 & 19 & Male & FG3 & 5 & 2 \\
\hline P16 & 19 & Male & FG3 & 5 & 3 \\
\hline P17 & 20 & Female & FG3 & 5 & 5 \\
\hline & & & & & 5 \\
\hline
\end{tabular}

The participants elaborated on the learning strategies and challenges faced in Phase 1 with online lectures and preparation and in-classroom Phase 2. Four dominant themes and ten sub-themes were identified from the views and experiences of the first-year pharmacy students: perceptions of FC, learning behaviours in FC, barriers to FC learning, and learning needs (Figure 1).

\section{Perceptions of FC}

\section{FC was a helpful learning approach}

Most students indicated i-lectures improved their knowledge regarding the subject matter and better prepared them for classroom learning. They also valued the teachers' role in elaborating on concepts or clarifying complicated ideas, providing examples, explaining how to solve a problem, and questioning their understanding during in-classrooms.
"If we cannot understand the i-lecture, we asked Dr $X$ (a lecturer) to explain the concept, and he continued elaborating on it till we understood." (P7)

\section{In-classroom technology (Kahoot!) motivates participation}

They revealed that most teachers used Kahoot! (a free game-based learning platform) or small group discussions during in-classroom. Kahoot! was particularly well received because it was "interesting" and "motivating". This was attributed to the competition and reward elements in Kahoot!, which boost students motivation to participate, as explained by one student:

"It is competitive, and that is why we are highly motivated. We do not get rewards, but we like seeing our names on the scoreboard." (P12)

\section{Learning behaviours in FC}

Planning, controlling of learning, and self-assessment during pre-classroom

Not all students have successfully prepared for all five in-classroom sessions. Students indicated that they had to plan their schedules to review the i-lectures (planning) because they needed a focus time to review the i-lectures, as one student explained:

"During the preparation, when I go through the $i$ lecture, once the i-lecture starts, I do not get up at all because if I pause and I go do something else, I forget where I paused it." (P14)

Review of the i-lectures mainly occurred the day before the respective in-classroom time due to students' hectic schedules. When students reviewed the ilectures, they indulged in the learning processes through play, forward, rewind, and pause of i-lectures to write down notes, clarify missed points or understand the content concepts (controlling of learning). To a lesser extent, some students compared the new learning to their written notes or searched for additional information. Some students also attempted quizzes (or formative questions) to gauge their understanding of the i-lecture (self-assessment). These learning processes are attributed to significant time spent beyond the i-lecture duration.

"The most recent one I remember was DrX $\mathrm{i}$-lecture. I took about two hours to do it because I have to read, and then I have to go through the i-lecture. I have to like write down what she said to relate to my notes also." (P13) 


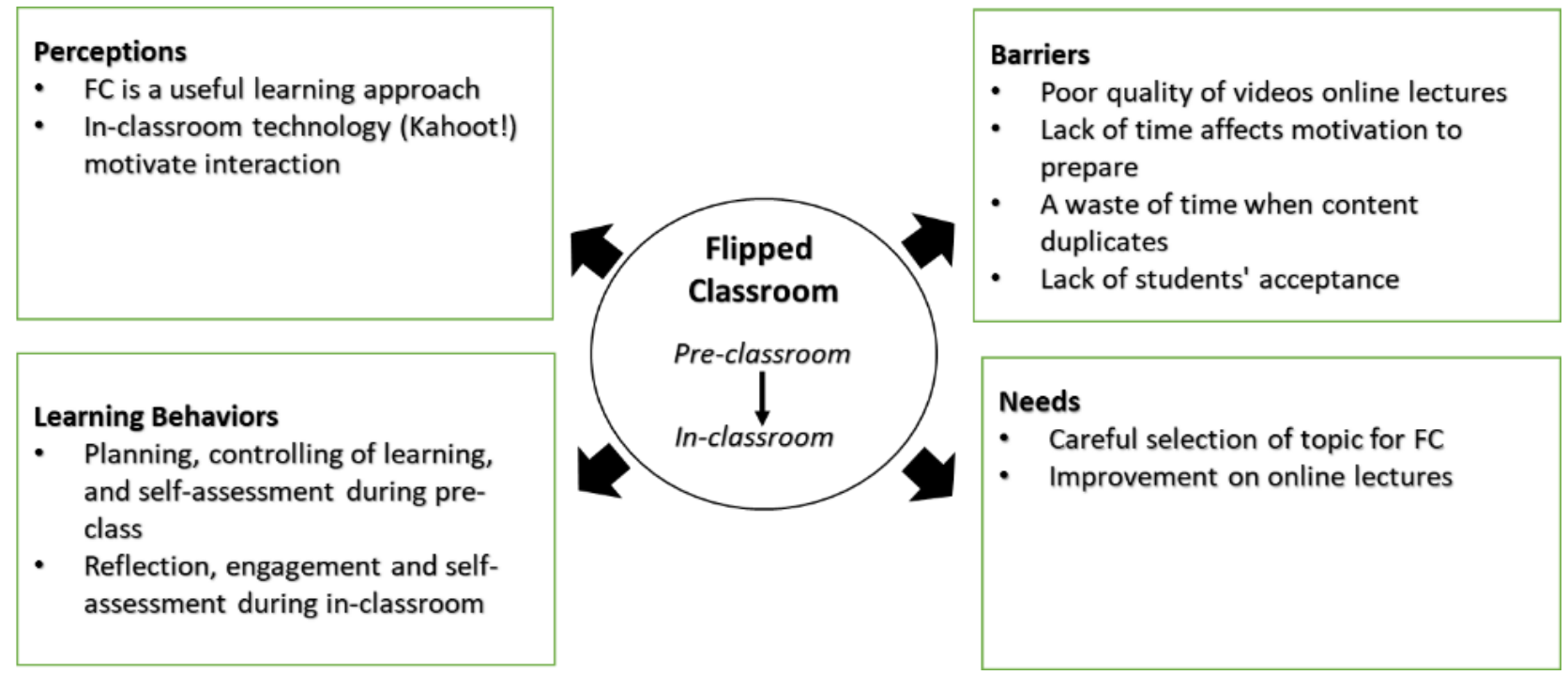

Figure 1: Themes and subthemes identified

\section{Reflection, engagement, and self-assessment during in-classroom}

Students appeared to have reflected and recognised the importance of preparing for the in-classroom session (reflection). They admitted to having felt lost if they did not prepare for the session. For students who had prepared before class, they would think and compare knowledge learnt (reflection) with information and explanation provided during the inclassroom. Questioning by teachers or quizzes through Kahoot! during in-classroom were essential to students learning. Through questioning, students could gauge their knowledge and gain more assurance of their learning (self-assessment).

"If I'm well prepared for the flipped classroom (inclassroom), I think it helps me understand better. The flipped classroom (in-classroom) have questions. For me, if I need to understand the topic, like completely understand everything, I need questions, I need to do questions, I need to practise them." (P6)

There were more teacher-student and student-student opportunities to interact (engagement) in FC as compared to a conventional lecture. Students would also raise questions and seek clarification which is encouraged by teachers.

"During the flipped classroom (in-classroom), we converse with the lecturers and among ourselves as some lecturers let us discuss the questions. " (P17)

\section{Barriers to FC learning}

Poor quality of online lectures

The most problematic part of FC was the preparation, which was attributed to the quality of i-lectures. Some i-lectures had poor audio quality, reading word-forword, a strong accent, and too much text. In the absence of subtitles, some students also encountered difficulties in understanding new medical jargon. The additional time and effort needed to review the $\mathrm{i}$ lectures were perceived as an additional burden and a hindrance.

"It was about forty minutes, so I only estimate like forty minutes that I can finish the video (i-lecture), but it turns out because I was writing and then I was like replaying. So it took me two hours" (P13)

\section{Lack of time affects the motivation to prepare}

Students acknowledged that the benefit of learning with the FC approach attributed to the motivation to do the pre-class activity. The motivation, however, was hampered by the lack of time. Students timetable was utterly packed with a rigorous course load. On the other hand, reviewing i-lectures was a time-consuming process. It was overwhelming, leading to the students being left with no time nor motivation to prepare for the in-classroom.

"This also depends on the timetable because sometimes the classes finish late and we might have three classes the next day" (P14) 


\section{A waste of time when pre-class content duplicates}

Despite the benefits of FC, the value of FC depends on the delivery; pre-class content and in-classroom content. When pre-class material content was highly similar to teaching content covered during inclassroom, there were uncertainties of its value.

"We already read the i-lecture before the flipped classroom (in-classroom). But there is a lot of repetitive (of teaching content). Time wasted in that sense" (P8)

\section{Large class size inhibits the interaction}

Some students admitted reluctance to verbalise during in-classroom despite encouragement by teachers. They tend to stay quiet during in-classrooms even though they had questions. The reasons were that they were "not comfortable" or shy to ask in large classroom sizes. There were also concerns that other students would see them as a "disruption to class" or "did not do their study" if they asked questions during class.

"When there are a lot of people around, we might not feel comfortable and relaxed. In that case, we cannot suddenly stand up and ask the lecturer, 'I do not understand this question'. We might feel ashamed." (P9)

\section{Lack of students' acceptance of learning using online lectures}

Despite the benefits of FC, not all students accept the use of the FC approach. They felt pre-class preparation using i-lectures is not suitable for every student. Some students viewed i-lectures as "boring", attributed either by how content was delivered (too much text) or repetitive actions of 'click' when watching the ilectures.

"I click the first part, then it (i-lectures) say click the second part, then I click the third part. It does not allow me to go to the next slide, and I have to return to the computer slide. I have to keep doing the same thing again and again, just to study. So it's like very boring for me." (P8)

For student claiming to a kinesthetic learner, the lack of touch and movement element of i-lectures was also deemed too ineffective for their learning.

"Online lecture is good for audio learners who like to listen while they study, but I am a kinesthetic learner, and I like to play in class." (P7)

\section{Learning needs}

Careful selection of topic for FC

Online lectures were viewed to be better suited for "less complex" content or concepts. For a fundamental or repetitive subject matter which could be understood through i-lectures, in-classroom was not even necessary. Students preferred conventional lectures for subject matter which is complicated or complex since the explanation is needed.

"The basic foundation and other similar content can be done through the flipped classroom approach. However, for new and complicated topics, I do not believe that the approach (FC) is feasible. It is complicated." (P5)

\section{Improvement on online lectures}

Students wished to have more time to prepare. Nevertheless, considering that the pharmacy course hectic academic timetable, they felt the i-lectures should be improved. The suggested improvement includes shorter online lectures, a more natural accent, more pictures and less text, a better explanation of concepts and not just details, more self-assessment tests, provision of subtitles, and accessibility through the mobile interface.

\section{Discussion}

The key feature of the FC in this study closely modelled the theoretical framework of the two-phase FC model discussed in multiple works of literature (Lage, Platt, \& Treglia, 2000; O'Flaherty \& Phillips, 2015). FC was generally viewed to be a helpful teaching method. In our study, in the pre-classroom, planning (schedule), controlling learning (over pace and sequence of ilectures), and self-assessment (using quizzes or formative questions) were reported. During inclassroom, students applied predominantly reflection (questioned and compared to prior learning), selfassessment (through Kahoot! and teachers' questioning), and engagement (with Kahoot!, peer and teachers). This finding supported the theoretical perspectives of self-regulation in FC (Rasheed et al., 2020), demonstrating first-year pharmacy students' ability to apply metacognitive processes such as planning, monitoring, controlling, and reflecting on their learning in the FC environment. These behaviours were inconsistently applied, indicating the need to support students' self-regulated learning in the transition to FC learning. 


\section{Pre-classroom learning}

We expected students to be autonomous learners who could take control of their learning in an FC environment. Although studies have indicated that online learning can result in better learning outcomes (Kong et al., 2014), our first-year pharmacy students felt overwhelmed due to challenges to learn using ilectures. The overwhelming challenges affected motivation and acceptance towards the use of ilectures.

Consistent with the previous study, students took substantial efforts and time to review pre-classroom videos (Cotta et al., 2016). Pre-classroom preparation took additional time because students also spent time on note-taking and looking up unfamiliar technical terms (Shibukawa \& Taguchi, 2019). Video quality (such as auditory quality, visual representation, ability to control) (Tomas et al., 2019) and the length of preclassroom videos greatly influence the learning. Short videos not only reduced extraneous cognitive load but was also associated with higher retention of knowledge and engagement in learning (Slemmons et al., 2018). Self-regulated learning supports can also be carefully designed to reduce dissatisfaction and enhance earning (Jansen et al., 2019). Supports, such as prompts in the form of encouragement or questions (e.g. explain what you have learnt ), can be provided, or instruction can be included to explain the benefits and ways to perform self-regulated learning activities (van Alten et al., 2020). Training on self-regulated planning (including readjusting plans) and time management are possibly valuable to equip all students with skills to apply strategies to learn consistently.

\section{In-classroom}

Our students engaged in varying levels of discussion with teachers and peers during in-classroom. Selfassessment quizzes, supported by technology, i.e. Kahoot! and peer discussion, engaged students in learning. The review supported the positive effect of Kahoot! on learning performance, classroom dynamics, attuites, and anxiety (Wang \& Tahir, 2020). Nevertheless, some students faced a challenge to feel safe and comfortable asking or expressing their thoughts openly due to the class size and potentially limiting students' learning. This finding is not surprising because larger class size often links to less preparation, less enthusiasm, lower effectiveness in stimulating interest and passivity among students (Monks \& Schmidt, 2011; Mulryan-Kyne, 2010). Forming engagement with students in large classes is also a challenge for teachers (Exeter et al., 2010).

Students in this study did not make a specific suggestion on class size. Literature has not also specified a limit in terms of the ideal class size for FC, but it is pointed out that "not all flipped classrooms are created equal" (McLaughlin et al., 2016). Smaller class size would be ideal for first-year FC to familiarise students with the collaborative learning environment. The exact class size should probably be considered in the change of teachers' pedagogical practice, such as using more active learning strategies (such as case studies, team simulations and role-playing, and challenging discussions) and feedback (Wright et al., 2017).

With increasingly demanding technology-based education as part of the 'new normal' education, more research is needed on the pedagogical practices of fully online FC, such as the Synchronous Online Flipped Learning Approach (SOFLA). The SOFLA model suggested a series of steps in which synchronous sessions consist of: whole group application, breakouts, share-out, preview and discovery, assignment instructions, and reflection (Marshall, 2017). Its applicability to students' engagement could be further investigated to support a thriving FC learning environment.

As a qualitative study, the findings may not apply to all pharmacy students. There may be potential participant bias as the samples recruited were confined to a single institution. Nevertheless, the adequacy of the sample in this qualitative study is evaluated by the quality of the data. As the data collection and analysis was based around students learning experiences and behaviours during the FC learning process, we would have missed impacts on learning and behaviours following FC learning. The study also excluded students who had not watched at least one i-lecture before the classroom and could have missed the opportunity to explore why students failed to prepare for FC. Future work should also consider a more longitudinal development of students learning behaviours with FC learning.

\section{Conclusion}

There was evidence of self-regulation in the FC environment among first-year pharmacy students. Participants' reservations toward FC stem primarily from the motivation and barriers to doing pre-class preparation. Therefore, there is a need to develop easy-to-learn and use pre-class learning materials tailored to students' level and preferences.

\section{Acknowledgments}

The authors acknowledge the students who had participated in this study and would also like to thank 
the International Medical University for the study approval and funding.

\section{References}

Akcayir, G., \& Akcayir, M. (2018). The flipped classroom: A review of its advantages and challenges. Computers and Education, 126, 334345. https://doi.org/10.1016/j.compedu.2018.07.021

Artino, A.R., \& Stephens, J.M. (2009). Academic motivation and selfregulation: A comparative analysis of undergraduate and graduate students learning online. The Internet and Higher Education, 12(3), 146151. https://doi.org/https://doi.org/10.1016/j.iheduc.2009.02.001

Baepler, P., Walker, J.D., \& Driessen, M. (2014). It's not about seat time: Blending, flipping, and efficiency in active learning classrooms. Computers and Education, 78, 227-236. https://doi.org/10.1016/j.compedu.2014.06.006

Butzler, K.B. (2016). The Synergistic Effects of Self-Regulation Tools and the Flipped Classroom. Computers in the Schools, 33(1), 11-23. https://doi.org/10.1080/07380569.2016.1137179

Chen, F., Lui, A.M., \& Martinelli, S.M. (2017). A systematic review of the effectiveness of flipped classrooms in medical education. Medical Education, 51(6), 585--597. https://doi.org/10.1111/medu.13272

Clarke, V., \& Braun, V. (2013). Successful Qualitative Research: A Practical Guide for Beginners. UK: Sage Publishing

Colthorpe, K., Ogiji, J., Ainscough, L., Zimbardi, K., \& Anderson, S. (2019). Effect of Metacognitive Prompts on Undergraduate Pharmacy Students' Self-regulated Learning Behavior. American Journal of Pharmaceutical Education, 83(4), 6646. https://doi.org/10.5688/ajpe6646

Cotta, K.I., Shah, S., Almgren, M.M., Macías-Moriarity, L.Z., \& Mody, V. (2016). Effectiveness of flipped classroom instructional model in teaching pharmaceutical calculations. Currents in Pharmacy Teaching and Learning, 8(5), 646-653. https://doi.org/10.1016/j.cptl.2016.06.011

Exeter, D., Ameratunga, S., Ratima, M., Morton, S., Dickson, M., Hsu, D., \& Jackson, R. (2010). Student Engagement in Very Large Classes: The Teachers' Perspective. Studies in Higher Education, 35, 761-775. https://doi.org/10.1080/03075070903545058

Gill, P., Stewart, K., Treasure, E., \& Chadwick, B. (2008). Methods of data collection in qualitative research: interviews and focus groups. British Dental Journal, 204(6), 291-295. https://doi.org/10.1038/bdj.2008.192

He, W., Holton, A., Farkas, G., \& Warschauer, M. (2016). The effects of flipped instruction on out-of-class study time, exam performance, and student perceptions. Learning and Instruction, 45, 61-71. https://doi.org/https://doi.org/10.1016/j.learninstruc.2016.07.001

Hew, K.F., \& Lo, C.K. (2018). Flipped classroom improves student learning in health professions education: A meta-analysis. $B M C$ Medical Education, 18, 38. https://doi.org/10.1186/s12909-018$1144-z$

Hu, R., Gao, H., Ye, Y., Ni, Z., Jiang, N., \& Jiang, X. (2018). Effectiveness of flipped classrooms in Chinese baccalaureate nursing education: A meta-analysis of randomized controlled trials. International Journal of Nursing Studies, 79, 94-103. https://doi.org/10.1016/j.ijnurstu.2017.11.012

Iwai, Y. (2020). Online Learning during the COVID-19 Pandemic: What do we gain and what do we lose when classrooms go virtual? Available at: https://blogs.scientificamerican.com/observations/onli ne-learning-during-the-covid-19-pandemic/

Jansen, R.S., van Leeuwen, A., Janssen, J., Jak, S., \& Kester, L. (2019) Self-regulated learning partially mediates the effect of self-regulated learning interventions on achievement in higher education: A metaanalysis. Educational Research Review, 28, 100292. https://doi.org/https://doi.org/10.1016/j.edurev.2019.100292

Kitzinger, J. (1995). Qualitative Research: Introducing focus groups. BMJ, 311(7000), 299-302. https://doi.org/10.1136/bmj.311.7000.299

Kong, S.C. (2014). Developing information literacy and critical thinking skills through domain knowledge learning in digital classrooms: An experience of practicing flipped classroom strategy. Computers \& Education, 78, 160-173. https://doi.org/https://doi.org/10.1016/j.compedu.2014.05 .009

Lage, M.J., Platt, G.J., \& Treglia, M. (2000). Inverting the classroom: A gateway to creating an inclusive learning environment. Journal of Economic Education, 31(1), 30-43. https://doi.org/10.1080/00220480009596759

Lai, C.-L., \& Hwang, G.-J. (2016). A self-regulated flipped classroom approach to improving students' learning performance in a mathematics course. Computers \& Education, 100, 126-140. https://doi.org/https://doi.org/10.1016/j.compedu.2016.05.006

Marshall, H.W. (2017). The synchronous online flipped learning approach. Available at: https://community.flglobal.org/thesynchronous-online-flipped-learning-approach

McLaughlin, J.E., White, P.J., Khanova, J., \& Yuriev, E. (2016). Flipped Classroom Implementation: A Case Report of Two Higher Education Institutions in the United States and Australia. Computers in the Schools, 33(1), 24-37. https://doi.org/10.1080/07380569.2016.1137734

Monks, J., \& Schmidt, R. (2011). The Impact of Class Size on Outcomes in Higher Education. The B.E. Journal of Economic Analysis \& Policy, 11, 62. https://doi.org/10.2202/19351682.2803

Mulryan-Kyne, C. (2010). Teaching large classes at college and university level: Challenges and opportunities. Teaching in Higher Education, 15(2), 175-185. https://doi.org/10.1080/13562511003620001

O'Flaherty, J., \& Phillips, C. (2015). The use of flipped classrooms in higher education: A scoping review. Internet and Higher Education, (25), 85-95. https://doi.org/10.1016/j.iheduc.2015.02.002

QSR International Pty Ltd. (2020) NVivo Available at: https://www.qsrinternational.com/nvivo-qualitative-dataanalysis-software/home

Rasheed, R., Kamsin, A., Abdullah, N., Kakudi, H., Ali, A., Musa, A., \& Yahaya, A. (2020). Self-Regulated Learning in Flipped Classrooms: A Systematic Literature Review. International Journal of Information and Education Technology, 10, 848-853. https://doi.org/10.18178/ijiet.2020.10.11.1469 
Roskvist, R., Eggleton, K., \& Goodyear-Smith, F. (2020). Provision of elearning programmes to replace undergraduate medical students' clinical general practice attachments during COVID-19 stand-down. Education for Primary Care, 1-8. https://doi.org/10.1080/14739879.2020.1772123

Sattar, K., Sethi, A., Akram, A., Ahmad, T., John, J., \& Yusoff, M. S. B. (2019). Flipped Classroom Teaching Modality: Key Concepts and Practice Endorsements. Education in Medicine Journal, 11(1), 1-10. https://doi.org/10.21315/eimj2019.11.1.1

Shibukawa, S., \& Taguchi, M. (2019). Exploring the difficulty on students' preparation and the effective instruction in the flipped classroom: A case study in a physiology class. Journal of Computing in Higher Education, 31, 9-10. https://doi.org/10.1007/s12528-019-09220-3

Slemmons, K., Anyanwu, K., Hames, J., Grabski, D., Mlsna, J., Simkins, E., \& Cook, P. (2018). The Impact of Video Length on Learning in a Middle-Level Flipped Science Setting: Implications for Diversity Inclusion. Journal of Science Education and Technology, 27, 1-11. https://doi.org/10.1007/s10956-018-9736-2

Sletten, S.R. (2017). Investigating Flipped Learning: Student SelfRegulated Learning, Perceptions, and Achievement in an Introductory Biology Course. Journal of Science Education and Technology, 26(3), 347-358. https://doi.org/10.1007/s10956-0169683-8

Tan, C., Yue, W.-G., \& Fu, Y. (2017). Effectiveness of flipped classrooms in nursing education: Systematic review and meta-analysis. Chinese Nursing Research, 4, 192-200. https://doi.org/10.1016/j.cnre.2017.10.006

Tomas, L., Evans, N. (Snowy), Doyle, T., \& Skamp, K. (2019). Are first year students ready for a flipped classroom? A case for a flipped learning continuum. International Journal of Educational Technology in Higher Education, 16(1), 5. https://doi.org/10.1186/s41239-019-0135-4

Tune, J., Sturek, M., \& Basile, D. (2013). Flipped classroom model improves graduate student performance in cardiovascular, respiratory, and renal physiology. Advances in Physiology Education, 37, 316-320. https://doi.org/10.1152/advan.00091.2013

van Alten, D.C.D., Phielix, C., Janssen, J., \& Kester, L. (2020). Self-regulated learning support in flipped learning videos enhances learning outcomes. Computers \& Education, 158, 104000. https://doi.org/10.1016/j.compedu.2020.104000

Wang, A.I., \& Tahir, R. (2020). The effect of using Kahoot! for learning - A literature review. Computers \& Education, 149. https://doi.org/10.1016/j.compedu.2020.103818

Wright, M., Bergom, I., \& Bartholomew, T. (2017). Decreased class size, increased active learning? Intended and enacted teaching strategies in smaller classes. Active Learning in Higher Education, 20(1), 146978741773560. https://doi.org/10.1177/1469787417735607

Zheng, B., Ward, A., \& Stanulis, R. (2020). Self-regulated learning in a competency-based and flipped learning environment: learning strategies across achievement levels and years. Medical Education Online, 25(1), 1686949. https://doi.org/10.1080/10872981.2019.1686949

Zimmerman, B.J., \& Moylan, A.R. (2009). Self-regulation: Where metacognition and motivation intersect. In Handbook of metacognition in education. (pp. 299-315). New York, NY, US: Routledge/Taylor \& Francis Group 